\title{
Co-regulation and knowledge construction in an online synchronous problem based learning setting
}

\author{
Lila Lee $^{1} \cdot$ Susanne P. Lajoie ${ }^{1} \cdot$ Eric G. Poitras $^{2}$ • \\ Miriam Nkangu ${ }^{3} \cdot$ Tenzin Doleck $^{1}$
}

Published online: 11 June 2016

(C) Springer Science+Business Media New York 2016

\begin{abstract}
Learning to monitor and regulate one's learning in an academic setting is a task that all students must engage in. Learning in "group" situations requires both selfand co-regulation. This research examines a case study of a small group of medical student interactions during an on-line problem based learning activity (PBL) where students learn to co-regulate their performance as they construct their understanding of how best to communicate bad news to patients. This paper introduces an approach for analyzing the group discourse to understand how collective knowledge building facilitates co-regulation. A mixed method analysis was used to analyze the case study data. A qualitative data analysis of verbal interactions was conducted to examine coregulatory episodes. Collective knowledge building was examined by analyzing the group discourse for indicators of co-regulatory processes. The study follows two quantitative analyses: a frequency count analysis of types of questions asked by facilitators and students; and a sequential pattern mining for patterns of cooccurrences of learners' discourse and co-regulation.
\end{abstract}

Keywords Collaborative knowledge building · Problem-based learning · Self-regulated learning $\cdot$ Co-regulation

\section{Introduction}

Learning theories emphasize the importance of active construction of knowledge and the manner in which multiple perspectives provided through social-cultural interactions

Tenzin Doleck

tenzin.doleck@mail.mcgill.ca

1 McGill University, Montreal, QC, Canada

2 University of Utah, Salt Lake City, UT, USA

3 University of Ottawa, Ottawa, ON, Canada 
lead to shared understanding (Greeno 2006; Hadwin, Järvelä, and Miller 2011; Levine, Resnick, and Higgins 1993; Valsiner and Van der Veer 2000). Knowledge building in collaborative learning situations can be enhanced when the activity is designed with the appropriate tools to support continuous discourse. Laferrière et al. (2010) defined knowledge building as "a collaborative effort directed towards creating and improving ideas" (p. 2). Collaborative learning is supported when there is a coordinated activity where learners construct and maintain a shared concept of a problem (Roschelle and Teasley 1995). In collaborative knowledge building, responsibilities for learning are shared and meaningful ideas are contributed from all the participants (Palincsar and Herrenkohl 2002). Student interactions can better provide opportunities for integration of new knowledge into pre-existing knowledge with cognitive processes leading to a collective understanding resulting in knowledge building (Bereiter 2002).

PBL supports collaborative knowledge construction and in the process learners develop skills of critical analysis, problem solving and content knowledge (Lajoie et al. 2014; Hmelo-Silver 2004). Research has established that effective selfregulation leads to better learning (Azevedo 2009; Pintrich 2000; Saab, van Joolingen, and van Hout-Wolters 2012; Winne and Perry 2000; Zimmermann 2008). However, we need to establish the mechanisms in which co-regulation occurs in the context of a group activity in terms of what leads to individual gains and mutual understanding of task demands ensuring task completion (Hadwin and Oshige 2011). Despite growing research on co-regulation, little is known about learners' knowledge construction processes in a collaborative problem-solving environment (Iiskala, Vauras, Lehtinen, and Salonen 2011). Social environments and instructional contexts support individual participation and learning (Volet, Summers, and Thurman 2009), however we need to understand how the group discourse leads to deeper understanding. Each learner, can bring different self-regulatory expertise to improve his/her self- and co-learning (Hadwin et al. 2011) by sharing the cognitive demands of the task leading to coregulation. Co-regulation assumes that the social group can ease the metacognitive and cognitive demands for each individual through the sharing of monitoring and regulating task processes (Lajoie et al. 2015; Hadwin and Oshige 2011; Lajoie and Lu 2012). Although the ultimate objective of co-regulation is to improve self-regulation there is a need to focus on learners' mutual regulatory activity during problem solving session to understand how members engage in productive collaborative learning. As Chan (2012) suggested when students engage in self-regulating their own learning as well as coregulating others' learning, productive group interactions are present. Co-regulation can be explored by studying group discourse and research has shown that three types of discourse moves enable knowledge building: questions, statements, and regulatory statements (Burbules 1993; Hmelo-Silver and Barrows 2008).

We examine the role of co-regulation in supporting collaborative knowledge building in the context of an on-line PBL activity. In this study we coded the PBL discourse to examine the types of questions, statements, and regulatory statements that occurred in the dialogue between facilitators and students to understand the characteristics of the interactions. Our assumption being that a large number of questions and statements would be an indication that students shared responsibilities for their own learning in collaborative knowledge building which would lead to a better understanding of the mechanisms of co-regulation. Most studies have agreed that students' questioning is critical in constructing collaborative knowledge. By asking questions, students make 
use of their prior knowledge, engage in a series of cognitive activities to construct new knowledge through the communication process (Burbules 1993). Knowledge is a product of social communication. Questions trigger the process of the collaborative knowledge construction, followed by discussion, argument, and clarification. In the context of collaborative learning, questions help individuals in the group to have a better understanding of the task, as well as monitor their own and each other's cognitive processes in order to complete the task. In the process of collaborative knowledge construction, teachers play a significant role in enabling students to develop their own focus with good inquiry questions. Teachers can pose open-ended questions and start the conversations with students to engage students in collaborative knowledge construction activities (Chi, Siler, Jeong, Yamauchi, and Hausmann 2001; King 1999).

We use Hadwin and colleagues' (2011) co-regulation definition, that co-regulation occurs in a social environment that supports self and other's participation and learning, to interpret the interaction between facilitators and students in PBL tutorial sessions. As such, we examine the discourse between students and facilitators to see how the types of questions, statements, and regulatory interactions explain the process of coregulation in the PBL. An in-depth qualitative and quantitative analysis of the verbal interactions is presented to extend our understanding of co-regulation. In this study, we examine the questions and statements generated by facilitators and students throughout the PBL sessions in order to understand how they lead to collective knowledge building that facilitate co-regulated learning. More specifically:

1. What are the types of questions asked by facilitators and students?

2. What is the relationship between co-regulatory episodes and categories of questions and statements generated by facilitators and students?

\section{Literature review}

\subsection{Collaborative knowledge building}

Knowledge building can be facilitated through constructivist learning environments such as a problem-based learning (PBL) environment that supports collaborative knowledge construction and in the process helps learners develop critical analysis, problem solving, and content knowledge (Hmelo-Silver 2004). Problem-solving and knowledge building are important since they promote critical thinking skills among students (Biggs and Tang 2011). Contemporary perspectives of learning emphasize active knowledge building and understandings (Brown and Campione 1996; Bruning, Schraw, and Ronning 1999). Students need to integrate effective learning individually and with peers. According to Dillenbourg (1999) and Teasley (1995), collaborative learning is achieved through interpretation and elaboration among group members. The performance of collaboration can be observed from interactions that facilitate learning: explanation, argumentation/negotiation, and mutual regulation (Dillenbourg, Järvelä, and Fischer 2009). Learners provide each other with opportunities to understand each others' perspectives which can lead to the co-construction of knowledge for better regulating learning processes. Furthermore, students in collaborative learning environments may engage in higher levels of cognitive activity (Ramsden 2003; Vauras et al. 
2003). Group interaction requires asking questions and providing detailed explanations that lead to higher levels of cognitive processes (King 2002). During collaborative learning, students can organize and incorporate their prior knowledge with new knowledge and develop mutual representations of understanding (Khosa 2014). Knowledge building is a discursive activity where learners share the responsibility to solve problems among themselves instead of solely relying on teachers. The shared responsibility enhances collective understanding. Students plan how to strategically figure out solutions to the problems as they set goals and apply their prior knowledge to the task at hand, and adjust their reflections through discussion (Bereiter 2002; Bereiter \& Scardamalia 2003; Scardamalia 2002). Students' active participation in a discussion is crucial to collaborative knowledge building (Rogoff, Matusov, and White 1996). In such a group activity, students become responsible for their own learning as they collectively build knowledge by incorporating each other's ideas as well as distributing expertise and sharing learning (Palincsar and Herrenkohl 2002). Ongoing discussion helps learners to build shared understanding.

\subsection{Discourse moves supporting collaborative knowledge building}

There are three important types of discourse moves that enable knowledge building: questions, statements, and regulatory statements (Burbules 1993). Questions initiate or inhibit a discussion and change direction of a dialogue. Statements consist in preparing, generating, exploring, and elaborating of ideas. Regulatory statements refer to statements that promote collaboration and learning processes. Students need to participate actively for identifying problems and exchanging their ideas in order to move a discussion forward. Hogan \& colleagues (1999) found in their studies that a group shows better performance and engagement if learners use questions to promote knowledge construction. Questions as well as metacognitive statements trigger the discussion for knowledge construction. Lajoie et al. (2015) demonstrated that metacognitive activity improved as the group discourse increased. Questioning plays an important role within the process of collaborative knowledge building. However, the specific roles and the importance of different types of moves are not fully supported. Questions can guide learners as to how to organize prior knowledge, how to set goals, how to monitor cognitive processes, and how to build knowledge together (Burbules 1993). Students can ask questions to check their mutual understanding of the problem, helping to develop a mutual cognitive representation of the problem. Questions can be used to refer to others' contributed knowledge to devise a strategic approach toward a solution. In the context of collaborative knowledge building, questions can lead the students to a correct understanding of the task but also to regulate cognitive processes towards their common goal (King 1999). Monitoring questions can help them to oversee the ongoing activity. According to Engle and Conant (2002), teachers' roles are particularly important in allowing students to question and challenge peers. In the context of a teacher-student learning environment, teachers provide open-ended questions to encourage student engagement and promote deeper understanding of the task at hand (Chi et al. 2001; King 1999). Teachers and students can bring out the desirable types of learning interaction by asking good questions (Chi et al. 2001; Graesser and Person 1994). Asking questions in the joint activity can support collaborative knowledge building. 


\subsection{Problem-based learning (PBL)}

Problem-Based Learning (PBL) is defined as active learning that is organized for small groups where teachers facilitate students using problems that are designed to stimulate problem-solving skills (Barrows 1996). Hmelo-Silver (2004) further defines PBL as an instructional method where students work collaboratively to solve ill-structured problems that may have more than one correct answer. PBL supports collaborative knowledge construction and in the process learners develop skills of critical analysis, problem solving and content knowledge (Hmelo-Silver and Barrows 2006; Hmelo-Silver 2004; Barrows 2000). Students become responsible for their own learning and progress collaboratively creating a shared group representation of knowledge (Greeno 1998; Hmelo-Silver 2004). The literature shows that medical students who practice PBL tend to demonstrate better knowledge application to their domain and more effective problem-solving skills than students who do not experience PBL (Hmelo 1998; Hmelo and Lin 2000; Schmidt et al. 1996). Facilitators are often teachers who support learners in their problem solving by monitoring the group discussions. Facilitators prompt students with questions based on their learning progression, encouraging deeper thinking processes when needed (Collins, Brown, and Newman 1989). Students try to understand the information given by their peers and incorporate it into their previous knowledge, creating a collective understanding. For collaborative knowledge construction, students ask questions and provide elaborate explanations. PBL encourages students to merge their learning into social environments promoting group discussion and peer interactions. PBL is defined as a constructivist learning environment where learners are directed to develop effective collaborative learning skills in socially contextualized situations where intrinsic motivation is increased as well (Dolmans et al. 2005). In other words, an interactive PBL environment rich in social contexts can enhance individual cognitive activities by bringing their own expertise that lead to better self-regulated learning (Hadwin et al. 2011).

\subsection{Co-regulation}

Effective regulation of student learning is an important condition for efficient learning (Saab, van Joolingen, and van Hout-Wolters 2012). In recent years, many researchers have emphasized the need to consider the social and cultural aspects of learning (Levine, Resnick, and Higgins 1993; Valsiner and Van der Veer 2000). Co-regulation is derived from Vygotsky's (1978) social-constructivist theory that describes how individuals' higher internal processes are supported within social contexts (McCaslin 2009; Wertsch and Stone 1985). As such, recent research has investigated co-regulation with respect to group cognition as each individual gains a mutual understanding of task demands as well as the activities that are mutually accomplished to ensure its completion (Hadwin and Oshige 2011). Despite growing research on co-regulation, little is known about learners' knowledge construction processes in a collaborative problemsolving environment and the instructional affordances of instructional materials (Iiskala, Vauras, Lehtinen, and Salonen 2011). In contrast to self-regulated learning (SRL), co-regulation directly involves the social aspect where group members can ease the metacognitive and cognitive demands by sharing, monitoring, and regulating task processes (Hadwin and Oshige 2011; Lajoie and Lu 2012). Students bring their own 
expertise to the activity and learn from each member's contribution to knowledge building. Co-regulatory activities imply that students are responsible for their own learning. Co-regulation is developed through dialogue and interaction to help learners to better regulate the cognitive demands of the task (Hadwin, Wozney, and Pontin 2005). The objective of co-regulation is to improve self-regulation. There is a need to focus on learners' mutual regulatory activity during problem solving session to understand how members engage in productive collaborative learning. Chan (2012) found that productive group interactions occur when there are high levels of individual selfregulatory activities as well as evidence of co-regulating others' learning. Co-regulation can be explored by studying group discourse to reveal social regulatory processes. In this study, we use Hadwin and colleagues' (2011) co-regulation definition to interpret the interaction between facilitators and students in PBL tutorial sessions. Their definition states that co-regulation occurs in a social environment that supports self and others' participation and learning. As such, we examine the discourse between students and facilitators to see how the types of questions, statements and regulatory interactions explain the process of co-regulation in the PBL. An in-depth qualitative and quantitative analysis of the verbal interactions is presented to extend our understanding of coregulation.

\subsection{Methodology}

The data presented in this paper were collected from an international on-line PBL designed to foster medical student learning about how to communicate bad news to patients. Students and physicians were from Canada and Hong-Kong. An expert PBL facilitator from the US supported the medical tutors from Canada and Hong Kong during the interactions. This paper deals with a subset of data from this PBL to explicitly examine the role of questions and how questions and statements influence co-regulatory episodes between facilitators and students.

\subsection{Participants}

In this case study four second and third year medical students volunteered to participate, two from a Canadian University (one female, one male) and two males from a Hong Kong University (referred to as $\mathrm{C} 1, \mathrm{C} 2$, HK1, \& HK2 respectively). The age range of the students was between 23 and 26 years old. Two experienced male physician educators (one from each country) referred to as facilitators (CF and HKF) and a female expert in PBL facilitator from the USA also participated. Data were collected on individuals as well as on the PBL groups.

\subsection{Procedures and materials}

Participants were part of a large pilot study designed to teach effective communication skills to an international group of medical students using technology. Data collection spanned over five consecutive days and consisted of five on-line synchronous/ asynchronous modules that were supported through web-conferencing software called Adobe Connect. Adobe Connect supported collaborative engagement through audio, video, and texts including notes and chats (Fig. 1). The PBL was considered the 


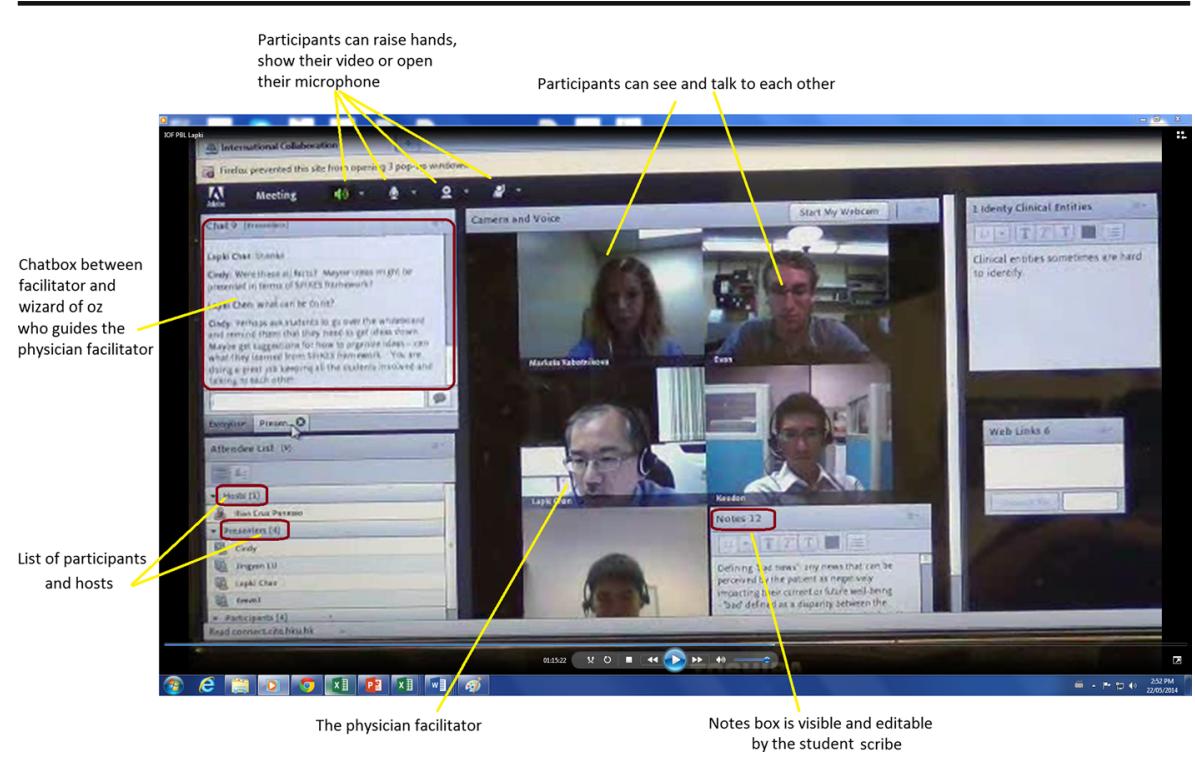

Fig. 1 Screenshot of Adobe Connect 9. Adapted with permission from (Lajoie et al. 2015)

intervention where students learned about the multiple considerations of how to give bad news. The pre-test was administered before the first PBL session on the 1st day and the post-test after the second PBL session on the 4th day. During pre and post-tests, individual medical students practiced giving bad news to standardized patients acting from a script given by physicians). On the 5th day there was a final debriefing session. For the purpose of this study, we will only focus on the two PBL sessions since they best reflect group activities where opportunities for different types of regulatory processes occurred.

\subsection{Problem-based learning (PBL)}

The PBL sessions were designed to teach medical students how to communicate bad news to HIV patients. A PBL is described as an inquiry-based instructional method that facilitates students learning through collaboration and problem-solving (Barrows and Tamblyn 1986; Hmelo-Silver and Barrows 2008; Lajoie et al. 2014). With the facilitators' guidance, students apply their prior knowledge, practice effective problem-solving and critically analyze the task (Hmelo-Silver 2004; Hmelo-Silver and Desimone 2013). The PBL sessions were contextualized to meet specific learning objectives in order for medical facilitators to assist students in: 1) determining issues with communicating bad news to a patient and strategies to address the difficulties; 2) providing examples of how best to deliver bad news; 3) analyzing a video illustrating a case of bad news communication using the SPIKES model (SPIKES is an acronym for how to conduct the patient interview when communicating bad news (Buckman 2005); it refers to setting the appropriate setting, assessing the patient's perception of the problem, invitation for patient to ask questions, knowledge provided to patient, empathy for patient, summary/strategies for follow-up when communicating bad news); and 4) discussing and reflecting on how the solution may have to be sensitive to contextual, cultural and language barriers. 
Abode Connect supported the PBL session by enabling synchronous video interactions. Two video cases were used on Days 1 and 2 of the PBL respectively. On Day 1, a simulated scenario of a North American doctor communicating a bad news to a patient, while a Hong Kong scenario case was prepared for Day 2. The Canadian video was in English and the Hong Kong case was in Cantonese with English subtitles, while English was the spoken language used by facilitators and students during the PBL session. The four participants decided on two roles: one student as a student facilitator and another student as a note-taker. They changed roles from one PBL to the next. An instructor and a PBL facilitator supported synchronous learning session by prompting and monitoring the group discussion through a private chat window in Adobe Connect.

\subsection{Research design}

A single case study approach was used to examine in depth an international on-line PBL for the discourse of medical students and facilitators (Yin 2009). This international group of participants creates a culturally rich medical case on how to better communicate bad news to patients. To address the research questions, a mixed methods approach was used. A qualitative analysis explored and identified dialogue moves for knowledge building and co-regulation. Frequency data and sequential pattern mining techniques were used to visualize answers for the research questions. For the purpose of this study, the 2 days of PBL sessions were analyzed. Both PBL sessions were captured with screen recording system and videotaped. The discourse of the PBL groups was transcribed verbatim and analyzed for evidence of collective knowledge construction and co-regulation activities. The first day PBL session was $124 \mathrm{~min}$ whereas the second day session lasted $140 \mathrm{~min}$. The two PBL sessions were combined into one data set resulting in $264 \mathrm{~min}$ of a discourse record.

The transcript of the two tutorial sessions were combined into one large corpus and examined at two different grain sizes: micro and macro. A micro grain size is a meaning unit whereas a macro grain size is an episode. A meaning unit is defined as a smallest unit with a common idea. A microanalysis was conducted on the data coding for three categories of questions ( 21 codes) and statements ( 9 codes). Co-regulation was coded at a macro level of episodes ( 5 codes). Each episode can contain a minimum of 2 turns and no maximum (Iiskala et al. 2011). The detailed description of codes is explained in the following section. A principal coder and a trained coder performed coding. Each time two coders coded a meaning unit differently was counted as a disagreement. For co-regulatory episodes, an episode coded with the same function was considered as an agreement. An episode does not require to start or end with a same segment. Coders solved all the disagreement by negotiation except two instances. The interrater reliability (Pearson correlation coefficient) for categories of questions and statements is $76 \%$ and for co-regulation codes is $84.5 \%$.

\subsection{Coding scheme}

The transcript was segmented twice using two different grain sizes. For the micro level codes, the unit of analysis was a meaning unit that is segmented based on common idea or from one person's turn (Chi 1997). A turn can be divided into several meaning units as one turn can contain different topics of discussion. A meaning unit was parsed into 
two units if it contained both a question and a statement. At the micro-level, there were 933 meaning units in the corpus, the principal investigator and another coder coded each meaning unit either for a question or a statement depending on the grammar and intonation of the unit (Graesser and Person 1994; Hmelo-Silver and Barrows 2008).

Questions and statements were coded to characterize facilitators and students contribution to the knowledge building discourse. Questions can lead students to build mutual understanding of shared tasks and regulate cognitive processes. Statements provide affordances for constructive processing by introducing ideas into group discourse and building on each other's ideas (Hmelo-Silver and Barrows 2008). These patterns of questions and statements allow researchers to understand how students engage in productive collaborative learning that will improve self- and co-regulation. For each question, it was noted if the speaker was a facilitator or student. We coded for three main categories that capture the depth of reasoning: short answers, long answers, and task-oriented/metacognitive questions divided, based on types of answers required, which differed throughout the sessions. These basic categories were further distinguished for specific activities. Short answers included verification, disjunctive, concept completion, feature specification, and quantification. Long answers were accompanied by more elaborated answers, those being either a definition, an example, a comparison, an interpretation, a causal antecedent, a causal consequence, an enablement, an expectational or judgmental comment. Task-oriented/meta questions were classified as referring to group dynamics, monitoring and reflective statements, self-directed learning or clarification comments, and requests/directives. The coding definitions and examples are provided in Table 1.

In order to understand how a group proceeds with collaborative knowledge building from each other's ideas, we examined statements that had been exchanged among facilitators and students. The categories of statements for collaboration are new idea, modification, agreement, disagreement, monitoring, reflection, directive, others, and no code. We modified the meta statement category from the original coding scheme. In order to better observe metacognitive processes among facilitators and students, the meta category has been split into two new categories: monitoring and reflection. Table 3 summarizes categories of statements with examples.

Co-regulation encompassed an "episode" as the macro level unit of analysis, and an episode consisted of a minimum of two turns and no maximum number of turns. We coded an episode as a co-regulation if the context as a whole represented co-regulation, even if some turns within the episode were non-relevant. The episode was analyzed in terms of function. Each category was defined according to the facilitation (active, confirm) or inhibition (slow, change) of group members' previous ideas leading to collective knowledge building. Exchanges of turns indicate facilitators and students were regulating together as they reacted to others' turns. The analysis of episodes can reveal how students engage in their own self- and co-regulatory strategies and processes. For instance, in an episode of activate code, a student introduces a new idea or concept related to the previous discussion. This can invite other students to join the conversation either asking questions to elaborate or providing statements that show their reflection. Co-regulation occurs when participants actively participate in sharing their expertise to learning in order to build a common task building mutual relationship (McCaslin 2009). 
Table 1 Questions coding definitions and examples

\begin{tabular}{lc}
\hline Codes & Definition \\
\hline $\begin{array}{c}\text { Short Answer } \\
\text { - Verification } \\
\text { - Disjunctive }\end{array}$ & $\begin{array}{c}\text { Yes/no responses to factual questions } \\
\text { Require a simple decision between two } \\
\text { alternatives }\end{array}$ \\
- Concept & Filling in the blank or the details of a \\
Completion & definition \\
- Feature & Determine qualitative attributes of an \\
Specification & object or situation \\
- Quantification & Determine quantitative attributes of an \\
& object or situation
\end{tabular}

Long Answer

- Definition

Determine meaning of a concept

- Example

- Comparison between two or more objects

- Interpretation

A description of what can be inferred from a pattern of data

- Causal

Antecedent

- Causal

Consequence

Request for instance of a particular concept or event type

sk for an explanation of what state or event causally led to the current state and why

Ask for explanation of consequences of event/state

- Enablement

Ask for an explanation of the object, agent, or processes allows some actions to be performed

\section{- Expectational \\ Ask about expectations or predictions (including violation of expectation) \\ - Judgmental \\ Ask about value placed on an idea, advice, or plan}

Task Oriented and Meta

$$
\begin{aligned}
& \text { - Group } \\
& \text { Dynamics }
\end{aligned}
$$

- Monitoring
Lead to discussions of consensus or negotiation of how group should proceed

Help check on progress, requests for planning
Examples

So you think it helps a lot?

Does it help at all, or it is really of no help?

What would be the main thing you would focus first?

Could we get general appearance?

How many steps should we take before giving bad news?

May I first suggest that we define what it means by bad news?

What would set in the preconsultation, consultation and post-consultation?

What about you, do you have experienced Hong Kong culture versus Australian culture?

Good, could you tell us more about "SPIKES"?

Leading to numbness and tingling? How that happens?

What happens when it's, when the, when the neuron's demyelinated?

Would you say that is probably the way a lot of people in Hong Kong, in Asian cultural people would react in that kind of situation?

How much, how much better is her, are her neural signs expected to get?

So how would you do it, like how would you obviously prepare the patient to give him the news that you have to go off in $30 \mathrm{~min}$ or so?

Do you want to share with us?

You bring it out very early on in our discussion he has a very, you know, mask face through out the consultation, right? 
Table 1 (continued)

\begin{tabular}{|c|c|c|}
\hline Codes & Definition & Examples \\
\hline $\begin{array}{l}\text { - Self-Directed } \\
\text { Learning }\end{array}$ & $\begin{array}{l}\text { Relate to defining learning issues, who } \\
\text { found what information }\end{array}$ & $\begin{array}{l}\text { So might that be a learning issue } \\
\text { we can, we can take a look at? }\end{array}$ \\
\hline $\begin{array}{l}\text { - Need } \\
\text { Clarification }\end{array}$ & $\begin{array}{l}\text { The speaker does not understand } \\
\text { something and needs further } \\
\text { explanation or confirmation of } \\
\text { previous statement }\end{array}$ & $\begin{array}{l}\text { What do you mean, you are more } \\
\text { or less polite when you are } \\
\text { with your Hong Kong } \\
\text { students? }\end{array}$ \\
\hline $\begin{array}{l}\text { - Request/ } \\
\text { Directive }\end{array}$ & $\begin{array}{l}\text { Request for action related to } \mathrm{PBL} \\
\text { process }\end{array}$ & $\begin{array}{l}\text { So, everyone is done with the } \\
\text { video? }\end{array}$ \\
\hline - Other & $\begin{array}{l}\text { Questions that do not fit into categories } \\
\text { above }\end{array}$ & Do you still hear me? \\
\hline - No Code & $\begin{array}{l}\text { The amount of information in a } \\
\text { particular segment not sufficient }\end{array}$ & Uh? \\
\hline
\end{tabular}

Codes and Definitions. Adapted from "Facilitating Collaborative Knowledge Building," by C. E. HmeloSilver and Barrows 2008, Cognition and Instruction, 26, 48-94

The coding scheme was taken from the study of Iiskala et al. (2011) as they coded for socially shared metacognition episodes. However, we redefined it for co-regulation in accordance with Hadwin's definition (2011) as mediating each other's cognitive learning. The five categories of co-regulation were activate, confirm, slow, change, and other of group understanding. Iiskala et al. (2011) includes another category ("stop") but this was not appropriate in this PBL context due to the long sequence of discourse. An illustration of this coding scheme is provided in Table 4.

\section{Results}

\subsection{Research question 1- what are the types of questions asked by facilitators and students?}

The questions are grouped into three identifying categories based on the coding presented by Hmelo-Silver and Barrows (2008): short answers (five sub-types: verification, disjunctive, concept completion, feature specification, and quantification), long answers (nine sub-types: judgmental, expectational, enablement, causal consequence, causal antecedent, interpretation, comparison, example, definition), and task-oriented and meta questions (sub-types: request/directive, need clarification, self-directed learning, monitoring, group dynamics). Figures 2, 3, and 4 present the frequency data for each of the three categories of questions. For each category of questions, the frequencies for sub-types of questions and the sum of all the questions were calculated. To simplify the comparison across question groups percentages were calculated for each sub-type question by taking the frequency of each sub-type question and dividing that by the total number of questions overall. This calculation is repeated for all three types of questions for the collapsed PBL transcript. We examined the distribution of different questions from students and facilitators for each category of questions. 


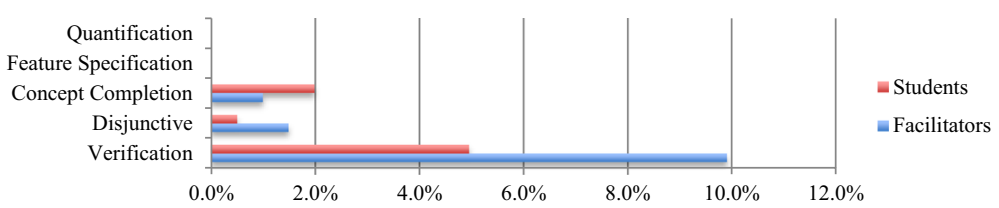

Fig. 2 Summary of Percentages for Short Answer Questions

\subsubsection{Short answer questions}

In the short answer category, five coded sub-questions are: verification, disjunctive, concept completion, feature specification, and quantification. The most frequently asked short answer question was a verification question for students $(5.0 \%)$ and facilitators $(9.9 \%)$. Students tried to check on each other's ideas as demonstrated by a Canadian student: "Didn't we all have the same standardized patient situation?" On the other hand, both students and facilitators rarely asked quantification and feature specification types of questions. Students need to construct a shared concept of the problem that will lead them to better knowledge construction activities. Short questions help students to understand the problem. Facilitators asked short answer questions as they monitored the learning processes among students as shown in the excerpt below (C1: a Canadian student, HKF: a facilitator from Hong Kong):

C1: And I think it really places a lot of the ideas thrown out yesterday into perspective. [Reflection - Statement]

HKF: So you think it helps a lot? [Verification - Question]

C1: Yes, to a certain extent, it helps to organize the thoughts. [Change Statement]

$2.0 \%$ of short answer questions generated from students were concept completion questions where students gather information to fill into the blank. For example, one of the students asked, "what are the procedures...like... about testing for HIV?" in order to get information about HIV testing steps in Canada. Then, disjunctive questions from students such as "did you find "SPIKES" or something else?" counted for $0.5 \%$. Disjunctive questions are ones that require a choice from two given alternatives. However, for facilitators disjunctive questions were $1.5 \%$ and concept completion questions were $1.0 \%$. Facilitators asked more questions to provide alternative choices for students and to verify learners' current understanding. Facilitators present ideas by

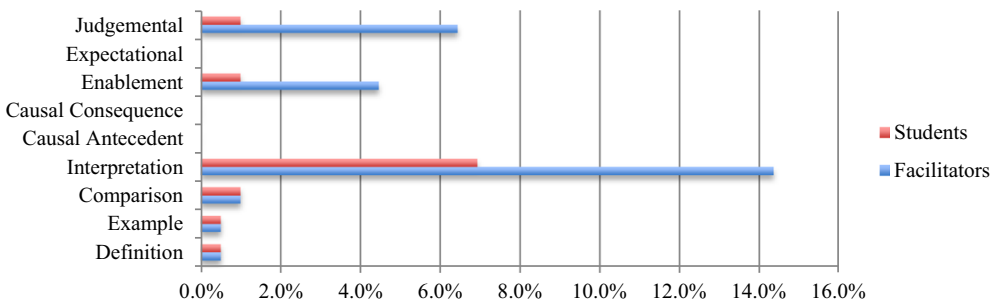

Fig. 3 Summary of Percentages for Long Answer Questions 


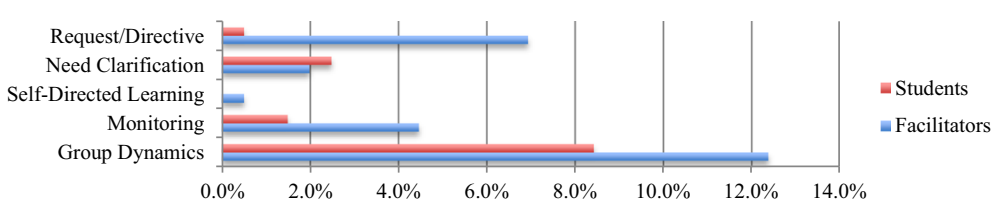

Fig. 4 Summary of Percentages for Task Oriented and Meta Questions

asking questions that provide two possibilities that may or may not have occurred to students' during the discussion. Students asked questions that require short answers to either clarify their understanding or request additional information.

\subsubsection{Long answer questions}

The second category of questions is long answer, which included nine sub-types defined activities (judgmental, expectational, enablement, causal consequence, causal antecedent, interpretation, comparison, example, definition) indicated in Fig. 3. We expected facilitators to engage students in deep thinking processes by asking questions that would require long answers. Medical students were expected to ask long answer questions to show that they are engaged in constructive learning processes.

As shown in Fig. 3, the three most prevalent types of long answer questions were: judgmental, enablement, and interpretation from both students and facilitators. On the other end of the spectrum, both students and facilitators rarely asked causal consequence and causal antecedent types of questions. For students, $6.9 \%$ of long answer questions were interpretation questions, which were used to help them interpret the information presented by others. For example, one student asks, "So, the points we have so far that he wrote, are um... how would we classify those things?" This student was not able to categorize one of the concepts that a student suggested during the PBL about organizing the consultation phase for presenting bad news to a patient. $14.4 \%$ of questions asked by facilitators are defined as interpretation questions. Facilitators are engaged to ask students to interpret the ideas and knowledge contributed by others in detail so that students can engage in deep cognitive activity to understand the material presented. Below is an excerpt that shows several examples of questions by the Hong Kong facilitator:

HKF: Even though you don't understand the language, Cantonese but just from the tone itself, you perceived something? [Interpretation - Question]

HKF: Well, well, I think, um... many of you think the tone, if you were the doctor so how would you do with the tone when you are talking, working? Show more emotion, empathy, understanding? [Enablement - Question]

HKF: Um, do you think the patient is very shock by the way that doctor delivers that news to him? [Judgmental - Question]

When facilitators ask students to elaborate on the data presented in the video by asking "how did the patient react to all these?" then students are encouraged to express their own ideas that lead to group progress in overall understanding. The long answer 
types of questions from facilitators and students support participants for elaboration and interpretation in order to extend collaborative knowledge construction. The second most frequently asked questions by facilitators are judgmental and enablement questions, $6.4 \%$ and $4.5 \%$ respectively. Facilitators encouraged students to contribute their own ideas and plans to other group members. For students, all three questions as judgmental, enablement, and comparison types counted for $1.0 \%$.

\subsubsection{Task oriented and meta questions}

The third category of questions is referred to as task oriented and meta questions, which included five sub-types defined activities, namely, group dynamics, monitoring, selfdirected learning, need clarification, and request/directive. The most frequently asked questions by both students and facilitators are group dynamics questions (Fig. 4) that encourages collaborative engagement and checking of others progression with respect to understanding and learning ( $12.4 \%$ by facilitators and $8.4 \%$ by students). On the other extreme, understandably, the least frequented question subtype was self-directed learning for both students and facilitators. The monitoring questions in the excerpt below shows that the Canadian facilitator monitored students' on-going discussion and provides questions that check on their progressive group understanding.

Once the question is posed students can modify the ideas being discussed or refine their knowledge. CF means the Canadian facilitator, $\mathrm{C} 1$ and $\mathrm{C} 2$ mean two Canadian students, and HK2 means a Hong Kong students.

CF: So, you seemed there's one step should occur before the other steps and so one and so forth? [Monitoring - Question]

C2: You want me to classify the points? [Need Clarification - Question]

C1: Do you have anything more that you would add to the pre-consultation phase? [Group Dynamics - Question]

HK2: Are there other important events that you guys know? [Group Dynamics Question]

Group dynamics questions engage the group members to offer any new ideas and express their understanding on the topic. From these questions, students can extend their reasoning from collaborative knowledge building and take responsibility for their own learning. The second and third most frequently asked questions by facilitators are request/directive $(6.9 \%)$ and monitoring $(4.5 \%)$ ones. Facilitators asked PBL process related questions as well as technology oriented questions to keep the group discussion moving while monitoring each learners' progress and understanding. Students asked clarification questions more frequently than monitoring questions, $2.5 \%$ and $1.5 \%$ respectively. Students needed to verify the concepts in order to progress in their own learning as they helped build a shared group representation. The distribution of questions asked by facilitators and students vary but all the questions generated help the students engage in a meta-level critical discussion to support the learning objectives. 


\subsection{Research question 2}

\subsubsection{A data mining approach}

The second research question was posed to ascertain the relationship between coregulatory episodes and categories of questions and statements generated by facilitators and students in the context of a PBL session. In order to examine learners' knowledge construction and co-regulation, we apply sequential pattern mining techniques to discover patterns in the co-occurrence of learners' states and behaviors during learning. More specifically, we examine the conditional probabilities where co-regulatory states co-occur during the PBL session. The discourse data was analyzed using a two-stage data mining technique. The first stage involves detection of significant relationships between dialogue moves among medical participants in the PBL group. For each coregulatory episode, the percentage of learners who engaged in one category of question and statement activities is assessed. This measure is repeated for all four co-regulatory categories (activate, confirm, slow, and change). The second stage involves generation and assessment of a heat map visualization of co-occurrences between co-regulatory episodes and questions and statements moves (Wilkinson and Friendly 2009).

The data mining approach employed for this study is similar to the sequential pattern mining method outlined by D'Mello et al. (2010) whose approach explored intrarelationships amongst the occurrence of coded segments of dialogue moves in tutoring transcripts using Eq. 1 below (see Kinnebrew, Segedy, and Biswas 2014; D’Mello et al. 2010). However in this study we modified the equation (see Eq. 2) since the analysis involves the detection of co-occurrences, referred to as the inter-relationships amongst codes, between two distinct types of dialogue moves. We examined the interrelationships of collective knowledge construction coded with categories of questions and statements and co-regulatory episodes applied to the same corpus of transcript at different levels of granularity. The likelihood metric formula below defines the likelihood of a distinct move at a given time $\left(M_{t}\right)$ given the next move $\left(M_{t+1}\right)$.

$$
\begin{aligned}
L\left(M_{t} \rightarrow M_{t+1}\right) & =\frac{\operatorname{Pr}\left(M_{t+1} \mid M_{t}\right)-\operatorname{Pr}\left(M_{t+1}\right)}{1-\operatorname{Pr}\left(M_{t+1}\right)} \\
L\left(M_{c_{i} t} \rightarrow M_{c_{j} t}\right) & =\frac{\operatorname{Pr}\left(M_{c_{j} t} \mid M c_{i t}\right)-\operatorname{Pr}\left(M_{c_{j} t}\right)}{1-\operatorname{Pr}\left(M_{c_{j} t}\right)}
\end{aligned}
$$

The revised formula (Eq. 2) is used in our analysis for inter-relationships since it deals simultaneously with both the categories of questions and statements (micro codes) and co-regulatory episodes (macro codes). The notation $\mathrm{C}$ is used to part the different categories of moves. The Eq. 2 allows the likelihood metrics to examine in contrast the conditional probability of both codes co-occurring, which is determined by $\operatorname{Pr}\left(\mathrm{M}_{\mathrm{cj}}\right) / \operatorname{Pr}\left(\mathrm{M}_{\mathrm{ci}}\right)$, with the expected degree of association, given that both are independent, as in $\operatorname{Pr}\left(\mathrm{M}_{\mathrm{cj}}\right)$. Therefore, the numerator of that formula is equal to the 
degree of co-occurrence between simultaneous defined classifications of codes minus the degree of co-occurrence meant to be under independence. A positive numerator indicates that the observed degree of co-occurrence is superior to the expected value under independence, whereas a negative numerator indicates that the recorded cooccurrence is inferior to the one expected under independence. If the numerator is equal to zero, then there is no co-occurrence between the two code categories. Therefore, the size and importance of $\mathrm{L}$ displays the direction and magnitude of the co-occurrence between $\mathrm{M}_{\mathrm{ci}}$ and $\mathrm{M}_{\mathrm{cj}}$, while taking into consideration the rate of $\mathrm{M}_{\mathrm{ci}}$ during the entire tutorial session's length.

\subsubsection{Data mining for co-occurrences}

The discourse was examined as a whole and we applied Eq. 2 to each discourse move in the corpus. The distribution of question types (short, long, and task-oriented/meta divided based on types of answers required - depth of reasoning) differed throughout the sessions. The frequencies of different categories of questions and statements were calculated and then transformed into percentages. For the percentages, we calculated the sum of each type of 21 questions and divided the resultant sum by the total number of questions for the transcript. This revealed the types of questions and statements that were occurring more frequently during the PBL sessions.

Among the 4 short answer type questions, one question called "verification" occurred most frequently throughout the session. In the long answer category question, 3 of them were most frequent (interpretation, enablement, judgmental). Four questions in taskoriented/metacognitive sub category were most frequently noticed: group dynamics, monitoring, need clarification and request/directive. For collaboration statement, new idea, modification, agreement, monitoring, and reflection occurred frequently. The frequencies of each co-regulatory episode were calculated. The most frequently occurring is the "activate" function of co-regulation with 20 occurrences out of 58 total co-regulatory episodes. The second most occurring episode is "confirm" (15) followed by "change" (13). In order to understand the characteristics of questions and statements in the coregulatory episodes, we examined qualitative excerpts for activate and change coregulatory episodes. Table 2 displays the frequencies of co-regulatory episodes and highly

Table 2 The frequency count of co-occurrences between co-regulatory episodes and types of questions

\begin{tabular}{llll}
\hline Co-Regulatory Episodes \& Categories of Questions & Rank & Frequency & $\operatorname{Pr}\left(M_{c j} \mid M_{c i}\right)$ \\
\hline Facilitate & & & \\
$\quad$ Activate \& Interpretation (Long Answer Category) & 1 & 30 & 0.21 \\
Activate \& Group Dynamics (Task oriented \& Meta Category) & 2 & 19 & 0.19 \\
Confirm \& Group Dynamics (Task oriented \& Meta Category) & 1 & 10 & 0.28 \\
Confirm \& Verification (Short Answer Category) & 2 & 8 & 0.22 \\
Inhibit & & & \\
Change \& Interpretation (Long Answer Category) & 1 & 10 & 0.22 \\
Change \& Group Dynamics (Task oriented \& Meta Category) & 2 & 8 & 0.17 \\
Slow \& Judgmental (Long Answer Category) & 1 & 1 & 1 \\
\hline
\end{tabular}


ranked co-occurred questions. We reported only the two highest ranked co-occurrences, as the others were significantly lower. The frequency shows the number of time both codes co-occurred in the entire corpus of discourse and $\operatorname{Pr}\left(\mathrm{M}_{\mathrm{cj}}\right) / \operatorname{Pr}\left(\mathrm{M}_{\mathrm{ci}}\right)$ gives the conditional probability of one micro codes co-occurred within one specific macro codes.

Co-occurrences of types of questions asked by facilitators and students varied in coregulatory episodes. Of the 5 co-regulatory episodes (activate, confirm, slow, change, and other), activate was the most predominant. Activate is one of the two codes that facilitates knowledge building by activating processes that lead to the integration of new knowledge and contributes meaningful ideas which are aligned with a previous thread of discussion. The most frequent types of questions that co-occurred in the activate episodes are interpretation and group dynamics. Interpretation questions require long answers that require deep reasoning compared to short answer category types. When students answer an interpretation question they need to describe in detail a particular concept or data presented. The inferences exchanged between group members help them to organize their current ideas and share common understanding of the problem. The second most co-occurring question is group dynamics from the task oriented and meta category. Group dynamics questions bring out consensus or encourage negotiation among group members to collaboratively construct knowledge. These questions can open up a dialogue for a shared concept of a problem. The conditional probability of interpretation question within activate co-regulatory episode is 0.21 . The excerpt below illustrates how students introduce a new topic for discussion derived from previous dialogue. In this section, the student leader asked most of the questions in order to organize the discussion among the group. The codes are inserted at the end of each segment and this excerpt is a partial body of the one activate co-regulatory episode (HK1: a Hong Kong student, C1 \& C2: Canadian students):

HK1: For example, consultation you can then analyze it as an icebreaking moment and then follow by a rapport building, something like that. [Activate Co-Regulation \& Modification Statement]

C1: So the points we have so far that HK1 wrote are um how would we classify those things? [Activate Co-Regulation \& Interpretation Question]

$\mathrm{C} 1$ : What would set in the pre-consultation, consultation, and post-consultation? [Activate Co-Regulation \& Example Question]

HK1: Um I think for pre-consultation phase, you can throw in just the tagging the bad news, preparing yourself about the bad news, revising about the patient's history, um. The track record o the patient, stuff like that. [Activate Co-Regulation \& Reflection Statement]

$\mathrm{C} 1$ : As $\mathrm{C} 2$ mentioned, just keeping a good environment that would be a preconsultation phase, something in there. [Activate Co-Regulation \& Agreement Statement]

C1: Ok, what you would think C2? [Activate Co-Regulation \& Group Dynamics Question] 
C1: You've been silent for a while. [Activate Co-Regulation \& Monitoring Statement]

C1: Do you have anything more that you would add to the pre-consultation? [Activate Co-Regulation \& Group Dynamics Question]

C2: Um...I would take a look at what's left. [Activate Co-Regulation \& Monitoring Statement]

C2: Well, maybe uh you know depending I guess on the situation and setting, you could determine if there is someone accompanying the patient at the point. [Activate Co-Regulation \& Modification Statement]

C2: What do you guys think? [Activate Co-Regulation \& Group Dynamics Question]

In this excerpt, the Canadian student leader asks an interpretation question to the other group members. This invites the other student to provide more detailed information about what he mentioned previously. HK1 answered with a reflective statement that brings out student's metacognitive process for how to prepare the pre-consultation phase. This statement led to an agreement statement based on the idea that another student mentioned previously. Using reflection and agreement statements, students can build on each other's ideas. Then, she continues prompting others to join by asking group dynamics questions that belong to task oriented and meta sub category question. Instead of providing a simple short answer the student encourages others to provide a response that requires deeper thinking. When students demonstrate a coregulatory episode that activates learning, the most frequently asked questions pertaining to interpretation and group dynamics (see Table 2). We see that long answer and task oriented/meta categories of questions help facilitate coregulation that activates new ideas in the line with previous discussion.

Questions that co-occur frequently with confirm co-regulatory episodes are short answer, task oriented and meta categories. Group members are confirming an idea that was previously constructed, in this case, confirming how students from different cultures would react in a particular situation. Confirm episodes facilitate cognitive processes leading to collective understanding. The conditional probability of group dynamics question is 0.28 occurring within confirm episodes. In the following excerpt, a Hong Kong facilitator is asking questions to invite students to confirm what they were discussing previously:

HKF: How they would react to that kind of bad news in Hong Kong, you were thinking that um in a different country the patient would react in a different way, right? [Confirm Co-Regulation \& Verification Question]

C1: Very likely but uh, I would just say that, there uh in Canada probably because of the history with uh people coming from a lot of different places. [Confirm CoRegulation \& agreement Statement] 
C1: We can end up with a lot of different variability in terms of the type of responses you might get from the patient because of their background and so it'll be a little bit harder to make to say what a typical response might be. [Confirm Co-Regulation \& Modification Statement]

HKF: Well that Hong Kong patient, same in Hong Kong I suppose. [Confirm CoRegulation \& Agreement Statement]

HKF: So what you were saying, basically you are saying the Hong Kong patient we saw on the video was reacting in a very calm way? [Confirm Co-Regulation \& Verification Question]

C1: Yup. [Confirm Co-Regulation \& Agreement Statement]

HKF: What do you think, HK1? [Confirm Co-Regulation \& Group Dynamics Question]

HKF: I mean HK2 as well, seems you were more familiar with the situation, the cultural situation, context in Hong Kong. [Confirm Co-Regulation \& New Idea Statement]

C1: Would you say that is probably way, a lot of people in Hong Kong, Asian cultural would react in that kind of situation? [Confirm Co-Regulation \& Enablement Question]

HK1:I would say um it is quite typical because you know in Hong Kong the consultation time would be less than 10 minutes for each patient so I would say most case it would not expecting any sort of patient physician communication, I think it is quite typical. [Confirm Co-Regulation \& Agreement Statement]

In this excerpt, students agree with the cultural differences that were discussed previously. The Hong Kong facilitator asks verification questions about a specific situation that happens in the video. With verification questions as "Does anyone find this?" students make complementary comments with agreement and modification statements. Rather than stop the thinking process these types of questions and statements facilitate knowledge building by contributing additional meaningful ideas into pre-existing knowledge. Facilitators often verify their thoughts before confirming the ideas that students bring to build knowledge collectively. Group dynamics questions bring consensus or negotiation from learners to participate actively in the discussion.

Interpretation and group dynamics questions can bring a new topic that is different than the previous dialogue direction by disagreement or suggestion of other alternatives. In terms of shifting the direction of the discussion, a similar pattern is found in the change co-regulatory episodes that inhibit the construction of a shared concept of the problem. A change co-regulatory episode is considered as inhibition of co-regulation but this does not mean that students do not regulate their learning. It is viewed as stopping one activity and restarting a new loop of dialogue. In doing so, group 
members can continue to monitor and regulate their cognitive process. The conditional probability for the co-occurrences in slow co-regulatory episodes and judgmental question moves resulted in a value of 1 . However, the fact that the actual frequency of that specific pair was 1 means that in practice it is not likely to occur at all. With a larger data set, we would find more slow co-regulatory episodes and this will probably increase the number of different categories of questions. As a result, we would not consider this code pair as an important activity. Questions such as verification, interpretation, and group dynamics are closely related to facilitating co-regulation. Students share ideas, identify the problem, and reach consensus jointly. To increase their collaborative knowledge construction, students built on each other's ideas using different types of statements. The co-occurrences of statements with specific co-regulatory episodes will be discussed in the following section with the heat map representation. It is important to consider the different categories of questions within co-regulatory episodes to better identify common patterns for facilitating aspects of self- and coregulation in interactive social presence.

\subsubsection{Heat map representation for co-occurrences}

In the following section, we demonstrate the use of heat map visualizations to facilitate the interpretation of these co-regulatory patterns. The heat map analysis will provide a better understanding of the affordances of this instructional event towards the impact of co-regulatory episodes of discussion on individual learners' collaborative knowledge construction activities. The heat map visualizations were used to highlight when any two distinct types of dialogue moves occur at the same time. Heat maps assign different colors to present visual representation of intra-relationships from highest to lowest values (Kinnebrew, Segedy, and Biswas 2014). The red color is assigned to the cooccurrences that are the most likely to occur and the blue color to the ones that are the least likely to occur. A white color is assigned for a base line with a value of zero. In this research, the visual representation of the inter-relationship amongst dialogue moves provides a deeper understanding of different types of questions' and statements' used during the PBL sessions. This approach makes an important contribution to the literature on educational data mining as current techniques are used to examine interrelationships amongst the occurrence of coded segments in the transcript as opposed to intra-relationships (see Kinnebrew, Segedy, and Biswas 2014; D’Mello et al. 2010).

The likelihood metric is a ratio between the conditional probability of one question type co-occurring with one co-regulatory episode and the probability of that question occurring within the same episode. We examined co-occurrences with the aim of identifying regularly occurring patterns of question moves and statements in coregulatory activities. The unit analysis consists of the 21 codes of questions (combining short, long, and meta categories of questions), 9 codes of statements, and 5 coregulatory episodes at the micro-level of granularity that are outlined in the coding scheme shown in Tables 1,3, and 4. The data set consists of $928 \mu$-level meaning units and 58 macro-level episodes. For the purpose of this paper, among all three categories of questions only the six codes of questions that occurred frequently during the PBL session are shown in Fig. 5 with co-regulatory episodes.

The results indicate that students shared responsibility for improving their collective understanding. The likelihood metric associated with the co-occurrence of 


\begin{tabular}{l|llllll}
\hline $\begin{array}{l}\text { Co-Regulatory } \\
\text { Episodes }\end{array}$ & \multicolumn{9}{c}{$\begin{array}{c}\text { Categories of Questions } \\
\text { Long Answer }\end{array}$} & \multicolumn{2}{c}{ Task Oriented \& Meta } \\
\hline & VER & INT & ENA & GRD & MON & DIR \\
Activate & & & & & & \\
Confirm & & & & & & \\
Slow & & & & & & \\
Change & & & & & & \\
Other & & & & & & \\
\hline
\end{tabular}

Fig. 5 Heat Map of Co-Occurrences between Co-Regulatory Episodes and Categories of Questions. Notes: Verification (VER); Interpretation (INT); Enablement (ENA); Group Dynamics (GRD); Monitoring (MON); Request/Directive (DIR)

interpretation question and activate co-regulatory episode equals 0.20 . This is the ratio between joint probability and conditional probability calculated during the first step of the analysis. There is a $20 \%$ probability that the two codes co-occur throughout the corpus of dialogues. The qualitative data also indicates that in active co-regulatory episodes, facilitators and students often ask questions as interpretation in long answer and group dynamics in task/oriented and meta categories. For example, facilitators ask group members questions to describe or infer from the information previous presented or newly contributed as: "what did you think was the perception of the patient in the video?" or "anything you gained from books or journal papers that help you to manage the kind of situations you saw on the video yesterday?"

When students are collaboratively regulating their learning in the direction of confirming current ideas, facilitators and students tried to verify or get consensus on information provided. Examples of group dynamics questions are: "good, so anyone of you were able to find anything else apart from "SPIKES"?", "What do you guys think?" or "What do the others think?" The likelihood of co-occurring confirms regulatory behavior at group level and group dynamics type of questions at the individual level is 0.26 . This means that there is $26 \%$ of chance of co-occurrences of above two codes during the two sessions of PBL. In a similar manner, a substantial number of verification questions were asked that require short answers. For example, the facilitator asked "silence, so it is useful too in your opinion, right?" Before deciding how to proceed next, medical students tend to verify their current construct as "Didn't we have all the same standardized patient situation?" These questions help students to reach consensus and facilitate contextualized learning process. 0.21 is the likelihood of asking verification questions at a given confirming group regulatory process. Questions that require long answers are presented less frequently. Facilitators and students require inference or description from data, explanation of processes or actions, and judgmental values for ideas or plans.

When students are planning to change the direction of previous activity in change co-regulatory episodes, the majority of questions are related to interpretation of the previous ideas or actions. They request more information related to current understanding such as "what would that mean to you if that was happening to you during an interview with an patient?" or "so the points we have so far that HK2 wrote are how would we classify those things?" The questions that needed more elaborate answer helped them to display their understanding. The likelihood of these two behaviors cooccurring is 0.21 . The likelihood of co-occurrence between other episodes and request/ directive question moves result in 0.30 . The other co-regulatory code means episodes that are not for a specific activity of co-regulation. Often collaborative discourse in the 
other episodes is more of organization related task and PBL organization related discussion. However, this is a good indication of participants are working together to create a better collaborative learning environment.

In order to understand how students build on each other's ideas for developing collective knowledge, we examined different categories of statements that are significant. The result of the sequential pattern mining technique shows that the likelihood of witnessing reflecting and thinking about previous actions within slow co-regulation episodes is 0.38 . Slow is considered as an inhibiting co-regulatory episode as it will slow down the continuation of discourse flow in the previous direction by monitoring and providing clarification. These episodes try to regulate cognitive processing towards their common understanding making sure that everyone shares same concept of the problem using metacognitive statements. Reflecting statements indicated that students were collaboratively building the knowledge from each other's ideas mentioned previously. Both metacognitive questions and statements support students' learning. For example, the exemplar below shows the on-going discussion in slow co-regulation episodes with several reflective statements from students (C1: a Canadian student, HK1: a Hong Kong student).

C1: so um I guess, what I cannot come to that conclusion without being exposed to SPIKES is hard to say, but SPIKES certainly helps finding what things were missing what things were may be done too much I guess [Slow Co-Regulation \& Reflection Statements]

HK1: I mean a good comparison which is to yesterday's session, I think yesterday we picked up a lot of things and ideas and facts as well, but ar it is kinda messy unlike today, today we are able to say yup, I know where this fits, Yup, I can say this properly. [Slow Co-Regulation \& Reflection Statement]

HK1: But yesterday we were trying to find words, so I think SPIKES helped to put it in words and to be able to communicate to other medical students who read SPIKES and who hear of SPIKES. And everyone could see where this fact would fit. [Slow Co-Regulation \& Reflection Statement]

As shown in Fig. 6, the majority of statements within activate and change coregulation episodes offer new ideas and modify the presented ideas. For students to build knowledge collaboratively, they need to negotiate their ideas and elaborate them with the modification statement type. This explains the high likelihood of new idea and modification statements $(0.24$ and 0.30 respectively) leading to revision or changing ideas and introducing new ideas in both co-regulation episodes. In future work we can

\begin{tabular}{lllll}
\hline \multirow{2}{*}{ Co-Regulation } & \multicolumn{4}{c}{ Categories of Statements } \\
\cline { 2 - 4 } & New idea & Modification & Monitoring & Reflection \\
\hline Activate & & & \\
Confirm & & & \\
Slow & & & \\
Change & & & \\
Other & & & \\
\hline
\end{tabular}

Fig. 6 Heat Map of Co-Occurrence between Co-Regulatory Episodes and Statements 
test this high likelihood of co-occurrences as hypotheses with a larger data set. Individual statements were simple statements but in co-regulation they were elaborated upon over several conversational turns. These results demonstrate that students took collaborative responsibility to construct knowledge. From the heat map representations, the medical students are engaged in collaborative knowledge building using different types of questions and statements. The facilitators help improve their ideas by asking open-ended questions. Students ask high-level questions from long and meta categories that enable them to develop effective collaborative learning skills.

\section{Conclusion}

Group discourse provides a lens for examining how collective knowledge building facilitates co-regulated learning. Small group work learning is fostered in varying forms in all levels and domains of education (Polman 2004) and consequently, we must understand how group interactions lead to knowledge building. Promoting on-going group interaction is crucial to encourage collaborative knowledge building when students are solving a case in PBL (HmeloSilver and Barrows 2008). This research was designed to reveal the nature of group discourse in a small-group PBL environment for medical students with the intent of demonstrating the relationship between group interactions and coregulatory activities that lead to knowledge building at both the individual and group level.

Empirical findings from the present study indicate that questions are at the core of collaborative knowledge construction (Dilson 1982; Graesser and Person 1994). When students ask questions, they not only use their prior knowledge, but also check their mutual understanding of the cases. Medical facilitators can play an important role of enabling students to question, which increases desirable learning interactions and promotes collaborative knowledge construction (Hmelo-Silver 2004). The findings indicate that a key component of co-regulation is shared task monitoring. Individual and group-regulated learning are facilitated when monitoring tasks are shared (Järvelä and Hadwin 2013; Lajoie and Lu 2012). This study indicates that the types of questions posed during the PBL led to deeper reasoning as students shared responsibility for constructing and maintaining a shared concept of a problem. Medical students and facilitators asked more questions that required long answers and were task oriented/ meta questions. Interpretation and judgmental long answer questions lead students to explain what they learned and apply their ideas or plans. Group dynamics and monitoring meta questions lead groups to engage in discussions inviting everyone to participate. The group discourse revealed a high percentage of open-ended questions that required deep reasoning, and as such the answers to such questions led to meaning making through shared group participation.

The discourse analysis revealed that certain types of questions and statements are present in co-regulatory episodes as group members refine and improve their collective knowledge. In particular, there were more statements that facilitate co-regulatory processes leading to shared understanding than statements that inhibit co-regulation. High occurrences of positive co-regulatory episodes were revealed in the discourse moves. A strong connection between co- 
regulatory episodes and metacognitive questions and statements were found. For example, interpretation and group dynamics questions were found most frequently in the activate co-regulatory episodes where students regulate other's learning by activating new ideas in the same direction as previous knowledge. These types of questions and statements helped facilitators and students to monitor the group learning process. In particular, interpretation questions accounted for the highest likelihood value $(20 \%)$ in the activate coregulatory episode followed by $21 \%$ in the change episode. Students focused on interpreting individual ideas from group members then refined their own ideas by connecting their ideas with the new information. Knowledge building is triggered by questions that were present in both the facilitating and inhibiting co-regulatory episodes. These activities led to a shared concept of the problem which co-occurred with better self-regulation and regulation of each other's learning. Group members answer questions mainly with modification statements that provide additional information or more details leading to better construction of collaborative knowledge. Often, metacognitive statement categories as monitoring and reflection facilitate co-regulation allowing students to build a deep understanding of the problems. The study of questions and statements in PBL discourse moves revealed students constantly check their mutual understanding and monitor ongoing activities that facilitate collaborative knowledge building in co-regulation.

This study makes an important theoretical contribution by adding to the literature in a manner that helps provide operational definitions of self-regulation, co-regulation, and knowledge construction, in the context of a PBL more specifically. Learning in any environment requires learners to regulate their learning however learning in small groups requires both self and co-regulation to achieve mutual understanding and collaborative knowledge building. Previous studies have indicated that knowledge construction takes place when students are actively engaged in their own and other's learning (Rogoff, Matusov, and White 1996). This study identified the role that collaborative knowledge construction plays in PBL. In medical situations, knowing what one knows and does not know can lead to saving a patient's life. These findings have instructional implications that can be tested in other domains to see if increasing specific types of questions will lead to more effective co-regulation. Another instructional implication is that computer-supported collaborative learning was a useful tool for facilitating students' SRL skills as well as students' coregulation (Lajoie and $\mathrm{Lu}$ 2012). The findings obtained from this pilot study are limited to the case study analysis and consequently the data are not sufficient to claim generalizability. However, the findings can be used to generate testable hypotheses in future studies that will examine the significance of these patterns as they occur across multiple PBL groups. The broader implications of this study are the replicability of the methodological and analytical approach used to study discourse moves towards the temporal unfolding of co-regulation in collaborative PBL settings. The instructional goal is to improve learning in small groups by fostering a community of learners to co-construct knowledge about how best to communicate with patients in a manner that leads to better treatment and patient care. 


\section{Appendix}

Table 3 Statements coding and examples

\begin{tabular}{|c|c|c|}
\hline Codes & Definition & Examples \\
\hline \multicolumn{3}{|l|}{ Collaboration } \\
\hline - New Idea & Mention idea not previously introduced & I found something about "SPIKES". \\
\hline - Modification & $\begin{array}{l}\text { Change an idea previously } \\
\text { mentioned - may include elaboration, } \\
\text { clarification, revision }\end{array}$ & $\begin{array}{l}\text { Theories just help looking through } \\
\text { the sort of theory that would fit } \\
\text { at all again it cannot be taught, } \\
\text { but it can be perfected through practice. }\end{array}$ \\
\hline - Agreement & $\begin{array}{l}\text { Indication of shared opinion } \\
\text { or understanding }\end{array}$ & $\begin{array}{l}\text { I think having the SPIKES model } \\
\text { like refreshing my mind, as it } \\
\text { was very well explained by the } \\
\text { ar, other three medical students. }\end{array}$ \\
\hline - Disagreement & $\begin{array}{l}\text { Indication of difference of opinion } \\
\text { or understanding }\end{array}$ & $\begin{array}{l}\text { Um... see the thing, I am not quite } \\
\text { sure, is some of the ideas but... }\end{array}$ \\
\hline - Monitoring & $\begin{array}{l}\text { Checking ongoing individual or } \\
\text { group progress; include awareness } \\
\text { of understanding }\end{array}$ & $\begin{array}{l}\text { I think, this is a very fruitful discussion, } \\
\text { I mean, I don't know }\end{array}$ \\
\hline - Reflection & $\begin{array}{l}\text { Thanking about specific actions and } \\
\text { their outcomes from previous trials } \\
\text { to design current trial }\end{array}$ & $\begin{array}{l}\text { How to do them or whether to do } \\
\text { them or not, so I don't see them are } \\
\text { facts, I will see them as learning idea. }\end{array}$ \\
\hline - Directive & Action related to $\mathrm{PBL}$ process & $\begin{array}{l}\text { Um, I'm thinking we would have to } \\
\text { look at the white board. }\end{array}$ \\
\hline - Others & $\begin{array}{l}\text { Statement that do not fit into } \\
\text { categories above }\end{array}$ & Thank you, all \\
\hline - No Code & $\begin{array}{l}\text { The amount of information in a } \\
\text { particular segment not sufficient }\end{array}$ & Some of... \\
\hline
\end{tabular}

Codes and Definitions. Adapted from "Facilitating Collaborative Knowledge Building," by C. E. HmeloSilver and Barrows 2008, Cognition and Instruction, 26, 48-94

Table 4 Co-regulatory episodes coding and examples

\begin{tabular}{ll}
\hline Codes $\quad$ Definition & Examples \\
\hline
\end{tabular}

- Activate Activating a new construct in line with previous direction

\footnotetext{
- Confirm Confirming that the previous direction is correct
}

HK1: Because he is using a lot of sensory muscles and his eyes are wide you know as if he is popping out of the socket. But um how would that, what does that body language convey, like.

C1: Above all this, nervousness and anxiety. I would say.

HKF: well now I think you raised a point because it sounded all the same to you, you were almost saying that his voice is monotonous

C2: C2 there, yes. 
Table 4 (continued)

\begin{tabular}{|c|c|c|}
\hline Codes & Definition & Examples \\
\hline - Slow & $\begin{array}{l}\text { Slowing down a continuation } \\
\text { the previous direction }\end{array}$ & $\begin{array}{l}\text { HKF: So C1 you, you um, you didn't } \\
\text { look at um "SPIKES" model before this } \\
\text { you know this video conference session. } \\
\text { So if you were not exposed to this model } \\
\text { at all, um do you think you would have } \\
\text { made as much observation as we did } \\
\text { today? Well do you think the model helped. } \\
\text { C2: I think it is difficult to say. I do think } \\
\text { the model helped, but it helped me more } \\
\text { for categorizing I guess for the what. }\end{array}$ \\
\hline - Change & $\begin{array}{l}\text { Changing the direction } \\
\text { of previous activity }\end{array}$ & $\begin{array}{l}\text { HK2: Oh um, I was not using this model, } \\
\text { I was just yeah, as you say, just think of a way. } \\
\text { HKF: You are not using it, HK1? Would } \\
\text { you use it like you say? }\end{array}$ \\
\hline - Other & $\begin{array}{l}\text { Episodes that do not fit } \\
\text { into categories } 1-4\end{array}$ & \\
\hline
\end{tabular}

Codes and Definitions. Adapted from "Socially Shared Metacognition of Dyads of Pupils in Collaborative Mathematical Problem-Solving Processes," by T. Iiskala et al. 2011, Learning and Instruction, 21(3), 379-393

\section{References}

Azevedo, R. (2009). Theoretical, conceptual, methodological, and instructional issues in research on metacognition and self-regulated learning: A discussion. Metacognition and Learning, 4(1), 87-95.

Barrows, H. S. (1996). Problem-based learning in medicine and beyond: A brief overview. New directions for teaching and learning, 1996(68), 3-12.

Barrows, H. S. (2000). Problem-based learning applied to medical education. Springfield: Southern Illinois University School of Medicine.

Barrows, H. S., \& Tamblyn, R. M. (1986). Problem-Based Learning: An Approach to Medical Education. New York: Springer.

Bereiter, C. (2002). Education and mind in the knowledge age. Mahwah: L. Erlbaum Associates.

Bereiter, C., \& Scardamalia, M. (2003). Learning to work successfully with knowledge. In E. DeCorte, L. Verschaffel, N. Entwistle, \& J. V. Merrienboer (Eds.), Unraveling basic components and dimensions of powerful learning environments (pp. 55-68). Oxford England: Pergamon/Elsevier Science, Ltd.

Biggs, J., \& Tang, C. (2011). Teaching for quality learning at university: What the student does. Maidenhead: McGraw-Hill/Society for Research into Higher Education/Open University Press.

Brown, A. L., \& Campione, J. C. (1996). Psychological theory and the design of innovative learning environments: On procedures, principles, and systems. In L. Schauble \& R. Glaser (Eds.), Innovations in learning: New environments for education (pp. 289-325). Mahwah: Lawrence Erlbaum Associates.

Bruning, R. H., Schraw, G. J., \& Ronning, R. R. (1999). Cognitive psychology and instruction. Upper Saddle River: Merrill.

Buckman, R. (2005). Breaking bad news: The S-P-I-K-E-S strategy. Community Oncology, 2(2), 138-142.

Burbules, N. C. (1993). Dialogue in teaching: Theory and practice. Teachers College Press.

Chan, C. K. (2012). Co-regulation of learning in computer-supported collaborative learning environments: A discussion. Metacognition and Learning, 7(1), 63-73.

Chi, M. T. (1997). Quantifying qualitative analyses of verbal data: A practical guide. The Journal of the Learning Sciences, 6(3), 271-315.

Chi, M. T., Siler, S. A., Jeong, H., Yamauchi, T., \& Hausmann, R. G. (2001). Learning from human tutoring. Cognitive Science, 25(4), 471-533. 
Collins, A., Brown, J. S., \& Newman, S. E. (1989). Cognitive apprenticeship: Teaching the crafts of reading, writing, and mathematics. In L. B. Resnick (Ed.), Knowing, learning, and instruction: Essays in honor of Robert Glaser (pp. 453-494). Hillsdale: Erlbaum.

D’Mello, S., Olney, A., \& Person, N. (2010). Mining collaborative patterns in tutorial dialogues. JEDMJournal of Educational Data Mining, 2(1), 1-37.

Dillenbourg, P. (1999). Collaborative learning: Cognitive and computational approaches. advances in learning and instruction series. New York: Elsevier Science.

Dillenbourg, P., Järvelä, S., Fischer, F., et al. (2009). The evolution of research on computer-supported collaborative learning. In N. Balacheff, S. Ludvigsen, T. De Jong, A. Lazonder, \& S. Barnes (Eds.), Technology-enhanced learning (pp. 3-19). Netherlands: Springer.

Dilson, J. T. (1982). The multidisciplinary study of questioning. Journal of Educational Psychology, 74(2), 147-165.

Dolmans, D. H., De Grave, W., Wolfhagen, I. H., \& Van Der Vleuten, C. P. (2005). Problem-based learning: Future challenges for educational practice and research. Medical Education, 39(7), 732-741.

Engle, R. A., \& Conant, F. R. (2002). Guiding principles for fostering productive disciplinary engagement: Explaining an emergent argument in a community of learners' classroom. Cognition and Instruction, 20(4), 399-483.

Graesser, A. C., \& Person, N. K. (1994). Question asking during tutoring. American Educational Research Journal, 31(1), 104-137.

Greeno, J. G. (1998). The situativity of knowing, learning, and research. American Psychologist, 53(1), 5-26.

Greeno, J. G. (2006). Authoritative, accountable positioning and connected, general knowing: Progressive themes in understanding transfer. The Journal of the Learning Sciences, 15(4), 537-547.

Hadwin, A., \& Oshige, M. (2011). Self-regulation, coregulation, and socially shared regulation: Exploring perspectives of social in self-regulated learning theory. Teachers College Record, 113(2), 240-264.

Hadwin, A. F., Wozney, L., \& Pontin, O. (2005). Scaffolding the appropriation of self-regulatory activity: A socio-cultural analysis of changes in teacher-student discourse about a graduate research portfolio. Instructional Science, 33(5-6), 413-450.

Hadwin, A. F., Järvelä, S., \& Miller, M. (2011). Self-regulated, co-regulated, and socially shared regulation of learning. In B. J. Zimmerman \& D. H. Schunk (Eds.), Handbook of self-regulation of learning and performance (pp. 65-84). New York: Routledge.

Hmelo, C. E. (1998). Problem-based learning: Effects on the early acquisition of cognitive skill in medicine. The Journal of the Learning Sciences, 7(2), 173-208.

Hmelo, C. E., \& Lin, X. (2000). Becoming self-directed learners: Strategy development in problem-based learning. In D. Evensen \& C. E. Hmelo (Eds.), Problem-based learning: A research perspective on learning interactions (pp. 227-250). Mahwah: Erlbaum.

Hmelo-Silver, C. E. (2004). Problem-based learning: What and how do students learn? Educational Psychology Review, 16(3), 235-266.

Hmelo-Silver, C. E., \& Barrows, H. S. (2006). Goals and strategies of a problem-based learning facilitator. Interdisciplinary Journal of Problem-based Learning, 1(1), 21-39.

Hmelo-Silver, C. E., \& Barrows, H. S. (2008). Facilitating collaborative knowledge building. Cognition and Instruction, 26(1), 48-94.

Hmelo-Silver, C. E., \& DeSimone, C. (2013). Problem-based learning: An instructional model of collaborative learning. In C. E. Hmelo-Silver, C. A. Chinn, C. K. K. Chan, \& A. O’Donnell (Eds.), The international handbook of collaborative learning (pp. 370-385). New York: Routledge.

Hogan, K., Nastasi, B. K., \& Pressley, M. (1999). Discourse patterns and collaborative scientific reasoning in peer and teacher-guided discussions. Cognition and Instruction, 17(4), 379-432.

Iiskala, T., Vauras, M., Lehtinen, E., \& Salonen, P. (2011). Socially shared metacognition of dyads of pupils in collaborative mathematical problem-solving processes. Learning and instruction, 21(3), 379-393.

Järvelä, S., \& Hadwin, A. F. (2013). New frontiers: Regulating learning in CSCL. Educational Psychologist, $48(1), 25-39$.

Khosa, D. K. (2014). Processes of metacognitive regulation and knowledge co-construction in case-based collaborative learning at university (Unpublished doctoral dissertation) Murdoch University, Australia.

King, A. (1999). Discourse patterns for mediating peer learning. In A. M. O’Donnell \& A. King (Eds.), Cognitive perspectives on peer learning (pp. 87-117). Mahwah: Erlbaum.

King, A. (2002). Structuring peer interaction to promote high-level cognitive processing. Theory into Practice, 41(1), 33-39.

Kinnebrew, J. S., Segedy, J. R., \& Biswas, G. (2014). Analyzing the temporal evolution of students' behaviors in open-ended learning environments. Metacognition and Learning, 9(2), 187-215. 
Laferrière, T., Montane, M., Gros, B., Alvarez, I., Bernaus, M., Breuleux, A., Allaire, S., Hamel, C., \& Lamon, M. (2010). Partnerships for knowledge building: An emerging model. Canadian Journal of Learning \& Technology, 36(1).

Lajoie, S. P., \& Lu, J. (2012). Supporting collaboration with technology: Does shared cognition lead to coregulation in medicine? Metacognition and Learning, 7(1), 45-62.

Lajoie, S. P., Hmelo-Silver, C., Wiseman, J., Chan, L. K., Lu, J., Khurana, C., Cruz-Panesso, I., Poitras, E., \& Kazemitabar, M. (2014). Using online digital tools and video to support international problem-based learning. Interdisciplinary Journal of Problem-Based Learning, 8(2).

Lajoie, S., Lee, L., Bassiri, M., Cruz-Panesso, I., Kazemitabar, M., Poitras, E., Hmelo-Silver, C., Wiseman, J., Chan, L., \& Lu, J. (2015). The role of regulation in medical student learning in small groups: Regulating oneself and others' learning and emotions. Computers in Human Behavior, 52, 601-616.

Levine, J. M., Resnick, L. B., \& Higgins, E. T. (1993). Social foundations of cognition. Annual Review of Psychology, 44(1), 585-612.

McCaslin, M. (2009). Co-regulation of student motivation and emergent identity. Educational Psychologist, 44(2), 137-146.

Palincsar, A. S., \& Herrenkohl, L. R. (2002). Designing collaborative learning contexts. Theory into Practice, 41(1), 26-32.

Pintrich, P. R. (2000). The role of goal orientation in self-regulated learning. In M. Boekaerts, P. R. Pintrich, \& M. Zeidner (Eds.), Handbook of self-regulation: Theory, research, and applications (pp. 451-502). San Diego: Academic.

Polman, J. L. (2004). Dialogic activity structures for project-based learning environments. Cognition and Instruction, 22(4), 431-466.

Ramsden, P. (2003). Learning to teach in higher education. London: Routledge.

Rogoff, B., Matusov, E., \& White, D. (1996). Models of teaching and learning: Participating in a community of learners. In D. R. Olson \& N. Torrance (Eds.), Handbook of education and human development (pp. 338-414). Malden: Blackwell.

Roschelle, J., \& Teasley, S. D. (1995). The construction of shared knowledge in collaborative problem solving. In C. E. O’Malley (Ed.), Computer-supported collaborative learning (pp. 69-97). Berlin: Springer.

Saab, N., van Joolingen, W., \& van Hout-Wolters, B. (2012). Support of the collaborative inquiry learning process: Influence of support on task and team regulation. Metacognition and Learning, 7(1), 7-23.

Scardamalia, M. (2002). Collective cognitive responsibility for the advancement of knowledge. In B. Smith (Ed.), Liberal Education in a Knowledge Society (pp. 67-98). Chicago: Open Court.

Schmidt, H. G., Machiels-Bongaerts, M., Hermans, H., ten Cate, T. J., Venekamp, R., \& Boshuizen, H. P. (1996). The development of diagnostic competence: Comparison of a problem-based, an integrated, and a conventional medical curriculum. Academic Medicine, 71(6), 658-664.

Teasley, S. D. (1995). The role of talk in children's peer collaborations. Developmental Psychology, 31(2), 207.

Valsiner, J., \& Van der Veer, R. (2000). The social mind: Construction of the idea. Cambridge: Cambridge University Press.

Vauras, M., Iiskala, T., Kajamies, A., Kinnunen, R., \& Lehtinen, E. (2003). Shared-regulation and motivation of collaborating peers: A case analysis. Psychologia: An International Journal of Psychology in the Orient, 46(1), 19-37.

Volet, S., Summers, M., \& Thurman, J. (2009). High-level co-regulation in collaborative learning: How does it emerge and how is it sustained? Learning and Instruction, 19(2), 128-143.

Vygotsky, L. S. (1978). Mind in society: The development of higher mental processes. Cambridge: Harvard University Press.

Wertsch, J. V., \& Stone, C. A. (1985). The concept of internalization in Vygotsky's account of the genesis of higher mental functions. In J. V. Wertsch (Ed.), Culture, communication and cognition: Vygotskian perspectives (pp. 162-182). Cambridge: Cambridge University Press.

Wilkinson, L. \& Friendly, M. (2009). The History of the Cluster Heat Map. The American Statistician, 63(2), 179-184.

Winne, P. H., \& Perry, N. E. (2000). Measuring self-regulated learning. In P. Pintrich, M. Boekaerts, \& M. Seidner (Eds.), Handbook of self-regulation (pp. 531-566). Orlando: Academic.

Yin, R. K. (2009). Case study research: Design and methods (4th ed.). Thousand Oaks: Sage.

Zimmermann, B. J. (2008). Investigating self-regulation and motivation: Historical background, methodological developments, and future prospects. American Educational Research Journal, 45(1), 166-183. 